\title{
Indomethacin induced avascular necrosis of head of femur
}

\author{
K R Prathapkumar, I Smith, G A Attara
}

\begin{abstract}
Chemically induced avascular necrosis of bone is a well documented entity. Indomethacin is one of the causes of this condition but is often difficult to recognise. Review of the literature shows that only one case of indomethacin induced avascular necrosis has been reported in the English language between 1966 and the present.

The case of a young healthy man, who developed avascular necrosis of head of femur after prolonged administration of indomethacin, is reported here. (Postgrad Med f 2000;76:574-575)
\end{abstract}

Keywords: indomethacin; avascular necrosis

\section{Case report}

A 33 year old postman presented with pain in his right hip. He had previously suffered from sciatica secondary to an L4/L5 intervertebral disc prolapse. He took indomethacin $150 \mathrm{mg}$

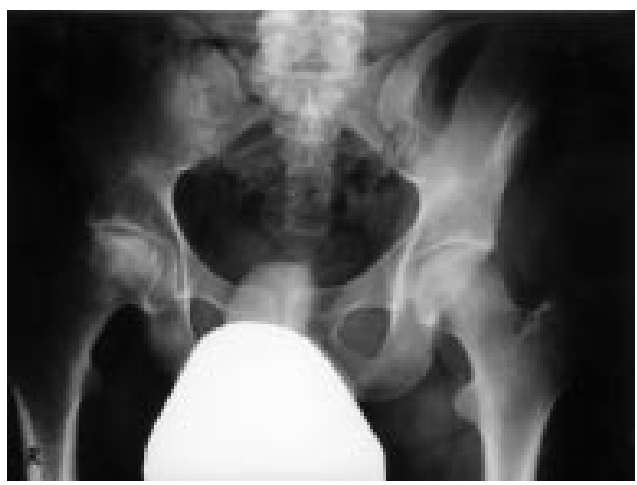

Figure 1 Radiograph, anteroposterior view, of pelvis with both hips showing collapsed right femoral head and sclerotic articulating surface.

Department of Orthopaedics, Gwynedd Hospital, Bangor, UK K R Prathapkumar I Smith

G A Attara

Correspondence to: Mr K R Prathapkumar, Flat No 2, H M Stanley Hospital, St Asaph, Denbighshire LL17 ORS (email: rajiprathap (a) netscapeonline.co.uk)

Submitted 22 March 1999 Accepted 13 January 2000

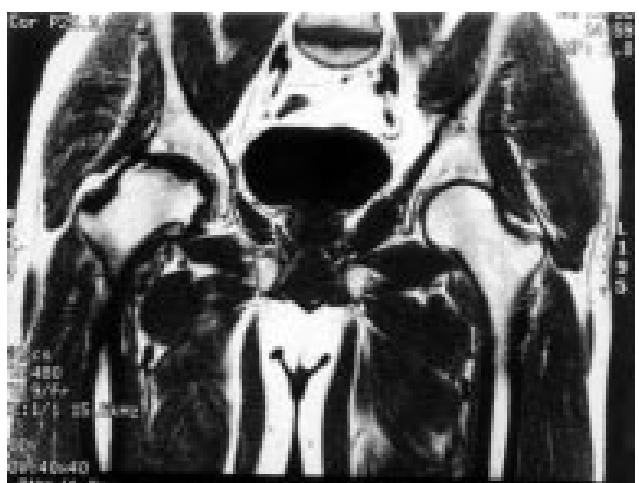

Figure 2 MRI scan of pelvis showing marked necrotic change of right femoral head with fragmentation. Appearance compatible with avascular necrosis of bone. daily for eight months before having laminectomy and discectomy. After surgery he was free of sciatic pain.

Four months after surgery he developed pain in the right hip. Radiography of the right hip taken at that time was normal. Indomethacin was again prescribed for two months with no relief of pain. He was not on steroids or any other medication and did not have any trauma to his right hip. Six months later he attended the orthopaedic clinic and at this stage clinical examination revealed a $15^{\circ}$ fixed flexion deformity of the affected hip and real shortening of $1 \mathrm{~cm}$. All movements of the right hip were restricted by pain.

All other joints were normal as was the general systemic examination. Radiography (fig 1) of the hip revealed collapse of the right femoral head due to avascular necrosis. His haematological and biochemical tests were normal. Magnetic resonance imaging (MRI) (fig 2) of his right hip revealed evidence of avascular necrosis while that of the left hip was normal.

\section{Discussion}

There are several causes of avascular necrosis of bone. But many cases are classified as idiopathic because of the difficulty in determining the cause. Chemically induced avascular necrosis of bone is well documented and indomethacin is one of the analgesic antiinflammatory agents implicated (box 1). The occurrence was first documented in $1968 .{ }^{1}$ The rate of articular destruction in indomethacin induced arthropathy is slower than that in steroid induced arthropathy. ${ }^{2}$ In this case, the patient took $45 \mathrm{~g}$ of indomethacin for a period of 10 months, before radiological diagnosis of avascular necrosis of head of femur was confirmed. This compares with the first reported case of avascular necrosis of head of femur, after indomethacin intake, in which a total amount of $105 \mathrm{~g}$ was implicated as the cause of the disease.

It has been presumed that the effect of indomethacin is primarily brought about by its analgesic effect, which predisposes to microfractures of weight bearing joints. Inhibition of healing of these microfractures may be important in pathogenesis of indomethacin induced avascular necrosis. Indomethacin reduces sulphate uptake in the articular cartilage of experimental animals. ${ }^{3}$ The sulphate uptake of chondrocytes reflected their proteinpolysaccharide synthesis, an important constituent of cartilage matrix. Indomethacin has 


\section{Box 1: Drugs causing avascular} necrosis of bone

- Corticosteroids

- Adrenocorticotrophic hormone

- Antimalignant drugs

- Arsenic compounds

- Ethanol

- Non-steroidal anti-inflammatory drugs:

Indomethacin

Phenylbutazone

Diclofenac

also been shown to produce a statistically significant depression of sulphated glycosaminoglycan synthesis in cartilage of the femoral head. ${ }^{4}$ These sulphated glycosaminoglycans and protein-polysaccharide compounds are important in the production of woven fibroid bone, which is the main factor in the fracture healing. Therefore indomethacin has the dual effect of predisposing the weight bearing joints to microfractures and concurrently inhibiting the healing of these fractures. ${ }^{5}$

Solomon's criteria (box 2) are an aid to making the diagnosis of drug induced avascular necrosis of bone and patients on long term
Box 2: Solomon's criteria for diagnosing drug induced avascular necrosis of bone

- High index of suspicion

- Definite history of drug intake before symptoms

- Clinical evidence of avascular necrosis

- Radiological evidence of avascular necrosis

indomethacin should be followed up regularly for early detection of avascular necrosis in weight bearing joints.

The authors thank Mr Alun Williams, Librarian, Gwynedd Hospital NHS Trust and Ms Mandy C Powell Orthopaedic Secretary, Gwynedd Hospital, Bangor.

1 Arora JS. Indomethacin arthropathy of hips. Proc R. Soc Med 1968;61:669.

2 Solomon L. Drug-induced arthropathy and necrosis of the femoral head. F Bone foint Surg Br 1973;55:246-61.

3 Watson $M$. The suppressing effect of indomethacin on articular cartilage. Rheum Rehab 1976;15:26-30.

4 Mckenzie L, Horsburgh BA, Ghosh P, et al. Effect of anti-inflammatory drugs on sulphated glycosaminoglycan synthesis in aged human articular cartilage. Ann Rheum Dis 1976;35:487-97.

5 Ro J, Sudmann E, Marton PF. Effect of indomethacin on fracture healing in rats. Acta Orthop Scand 1976;47:588-99. 